\title{
Omega-6 and omega-3 fatty acids: Endocannabinoids, genetics and obesity ${ }^{\text {负 }}$
}

\author{
Artemis P. Simopoulos* \\ The Center for Genetics, Nutrition and Health, 4330 Klingle Street NW, 20016 Washington DC, United States
}

Received 2 May 2019 - Accepted 11 October 2019

\begin{abstract}
The tissue composition of polyunsaturated fatty acids (PUFA) is important to health and depends on both dietary intake and metabolism controlled by genetic polymorphisms that should be taken into consideration in the determination of nutritional requirements, obesity and chronic disease risk. Experimental and clinical intervention studies suggest that omega- 6 and omega- 3 fatty acids have opposing physiological and metabolic properties and elicit divergent effects on body fat gain through mechanisms of adipogenesis, browning of adipose tissue, lipid homeostasis, systemic inflammation and an increase in the tone of the endocannabinoid system. Overweight and obese individuals have higher levels of the arachidonic acid (AA) derived endocannabinoid $\mathrm{N}$-arachidonoylethanolamine (AEA) and 2-arachidonoylglycerol (2-AG) and an altered pattern of receptor expression. Since endocannabinoids are products of dietary fats, modification of the omega- 6 and omega-3 fatty acid intake modulates the endocannabinoids, with eicosapentaenoic acid (EPA) and docosahexaenoic acid (DHA) displacing AA from cell membranes, reducing AEA and 2-AG production, resulting in decrease in appetite and food intake leading to weight loss. Polygenic risk scores reveal susceptibility and an increase risk for obesity. Therefore, persons at risk for obesity will have to lower omega- 6 and increase their omega- 3 fatty acid intake in order to have a balanced ratio for health. A process needs to be established to define when genomic discoveries such as gene-nutrient-disease associations are "ready" to be evaluated as potential tools for personalized nutrition to improve public health.
\end{abstract}

Keywords: omega-6 and omega-3 fatty acids / endocannabinoids / inflammation / obesity / genetic variants / polygenic score

Résumé - Acides gras oméga-6 et oméga-3 : endocannabinoïdes et obésité. La composition en acides gras polyinsaturés (AGPI) des tissus corporels est un déterminant de la santé de l'Homme. Elle dépend à la fois de l'apport alimentaire en AGPI et de leur métabolisme qui est sous le contrôle des polymorphismes génétiques, facteurs qui doivent être impérativement pris en considération dans la détermination des besoins nutritionnels mais également dans le risque de certaines pathologies comme l'obésité et les maladies chroniques. Des études nutritionnelles expérimentales et cliniques suggèrent que les acides gras oméga- 6 et oméga-3 possèdent des propriétés physiologiques et métaboliques opposées, suscitant des effets différents sur le gain de masse grasse via des mécanismes d'adipogenèse, de brunissement du tissu adipeux, d'homéostasie lipidique, d'inflammation systémique, mais également via une augmentation du tonus du système endocannabinoïde. Ainsi les sujets en surpoids et obèses présentent des taux plus élevés de Narachidonoyléthanolamine (AEA) et de 2-arachidonoylglycérol (2-AG), deux endocannabinoïdes dérivés de l'acide arachidonique (AA), ainsi qu'une altération de l'expression de leurs récepteurs spécifiques. Du fait que les endocannabinoïdes sont directement synthétisés à partir des AGPI issus de l'alimentation, une modification de l'apport alimentaire en acides gras oméga- 6 et oméga-3 va moduler significativement les teneurs corporelles en ces endocannabinoïdes. Ainsi comme les acides eicosapentaénoïque (EPA) et docosahexaénoïque (DHA) supplantent l'AA des membranes cellulaires, leur consommation réduit la production d'AEA et de 2-AG, ce qui entraîne une diminution de l'appétit et de la prise alimentaire et, par conséquent, une perte de poids corporel. Les scores de risque polygénique révèlent une susceptibilité et un risque accru d'obésité. Par conséquent, les personnes à risque d'obésité devront réduire leur consommation

\footnotetext{
H Contribution to the Topical Issue "Lipids and health / Lipides et santé".

*Correspondence: cgnh@bellatlantic.net
} 
d'acides gras oméga-6 et augmenter celle d'acides gras oméga-3 afin de maintenir un rapport équilibré entre ces 2 familles et optimisé pour leur santé. Dans un but de santé publique, il est maintenant urgent de mener de nouvelles recherches pour valider les associations gènes-nutriments-pathologies et d'en évaluer l'impact en tant que paramètres nutritionnels personnalisés.

Mots clés : acides gras oméga-6 et oméga-3 / endocannabinoïdes / inflammation / obésité / variantes génétiques / score polygénique

\section{Introduction}

Today, we know that linoleic acid (LA) and alpha-linolenic acid (ALA) are essential for normal growth and development of human beings (Simopoulos, 2010). The two families of omega-6 (LA) and omega-3 (ALA) fatty acids are physiologically and metabolically distinct, cannot be synthesized in the human body and must be obtained from the diet. Figure 1 shows the metabolism of LA and ALA into very long chain polyunsaturated fatty acids (LC-PUFAs) through a series of desaturases and elongases (Laye, 2015). Both LA and ALA use the same enzymes and compete with each other for enzyme availability. During evolution, there was a balance in the intake of LA and ALA with a ratio of $\omega-6: \omega-3=1$, whereas today in Western societies the ratio is about $16 / 1 \omega-6: \omega-3$ due to the high intake of vegetable oils-soybean, corn oil, sunflower,

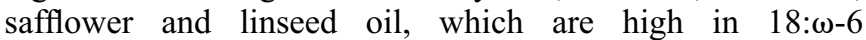
(Simopoulos, 2008). LA is found in high amounts in grains with the exception of flaxseed, perilla, rapeseed and walnuts that are rich in ALA. The green leaves of plants, particularly wild plants are higher in ALA than LA (Simopoulos, 1991, 2008, 2009; Simopoulos et al., 1992).

The capacity for desaturation and chain elongation of polyunsaturated fatty acids (PUFAs) appears to be limited and variable (Fig. 1). From isotope-labeled ALA feeding studies, the range of conversion of ALA to eicosapentaenoic acid (EPA) has been estimated between 0.2 and $21 \%$ (Burdge, 2004). The PUFA composition of phospholipids has been shown to be associated with normal growth and development, as well as in the outcome of chronic diseases such as coronary heart disease (CHD), hypertension, obesity, cancer, type 2 diabetes, arthritis, allergies and other autoimmune diseases, since both omega- 6 and omega- 3 PUFAs are processed to powerful promoters of eicosanoids such as prostaglandins and leukotrienes with opposing properties (Fig. 1) (Simopoulos, 1991, 2008; Simopoulos et al., 1992). The eicosanoids from AA are proinflammatory while those from EPA and DHA are anti-inflammatory. Furthermore, the production of resolvins, protectins and maresins from EPA and DHA are antiinflammatory (Fig. 2) (Hansen et al., 2019). Similarly, the endocannabinoids from AA are proinflammatory, increase appetite and food intake, while those from EPA and DHA are anti-inflammatory (Naughton et al., 2013). Thus, the balance of omega- 6 and omega-3 fatty acids is important for health. Omega- 6 fatty acids account for the majority of PUFAs in the US food supply (Simopoulos and Robinson, 1999). They are the predominant PUFAs in all diets, especially Western diets. The major omega- 6 fatty acid in Western diets is LA, representing about $90 \%$ of all the PUFAs in North American diets. Recently, Stark et al. (2016) showed that there are worldwide deficiencies in EPA and DHA in RBC's leading to a high omega-6/omega-3 ratio. High LA diets promote obesity in both humans and animals and are correlated with increased fasting blood glucose, fasting insulin, and insulin resistance in humans. The levels of LC-PUFAs in plasma, serum or RBC membrane phospholipids depend on dietary intake and endogenous metabolism (Simopoulos, 2010) (Fig. 1). There have been many indications for considerable interindividual variation in the capacity for endogenous formation of LC-PUFAs (Simopoulos, 2010). The dietary intake of AA, EPA and DHA determine the levels of endocannabinoids in brain, liver, adipose and other tissues (Naughton et al., 2013).

This paper focuses on genetic variants in the metabolism of omega- 6 and omega- 3 fatty acids, their opposing effects and endocannabinoids as they relate to the risk of obesity.

\section{Genetic variants, FADS1 and FADS2, in estimating nutritional requirements of omega-3 and omega- 6 fatty acids}

The key enzymes in omega- 6 and omega- 3 fatty acid metabolism are the delta-5 and delta- 6 desaturases, which are encoded by the fatty acid desaturase 1 (FADS1) and fatty acid desaturase 2 (FADS2) gene, respectively (Cho et al., 1999a, 1999b; Marquardt et al., 2000).

FADS1 and FADS2 are located on the desaturase gene cluster on chromosome 11 (11q12-13.1). This cluster also includes a FADS3 gene that shares 52 and $62 \%$ sequence identity with FADS1 and FADS2 genes, as well as a cytochrome b5 domain and a multiple membrane spanning desaturase region.

In 2006, Schaeffer et al. (2006) were the first to show that common genetic variants of the FADS1 and FADS2 gene cluster and their reconstructed haplotypes are associated with the fatty acid composition in serum phospholipids $\left(P\right.$-values $\left.<1.0 \times 10^{-13}\right)$. Subjects carrying the minor alleles of the single nucleotide polymorphisms (SNPs) rs 174544, rs 174553 , rs 174566 , rs 174561 , rs 174568 , rs 968567 , rs 99780, rs 174570, rs 2072114, rs 174583 and rs 174589 were associated with increased levels of 18:2 $\omega-6,20: 2 \omega-6,20: 3 \omega-$

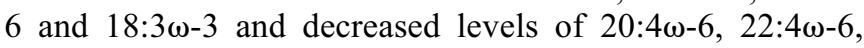
$20: 5 \omega-3$ and 22:5 $\omega-3$. A significant decrease of AA and EPA and dihomo- $\gamma$-linolenic acid is associated with decreased production of strong inflammatory mediators. Oleic acid $18: 1 \omega-9$ and $22: 6 \omega-3$ did not show statistically significant associations with the genetic variants. The investigated SNPs in this cluster explained $28 \%$ of the variance of AA and up to $12 \%$ of its precursor fatty acids. The frequency of the minor alleles was about $26 \%$. It can be concluded that the genetic variants indicate a difference in the conversion of omega- 6 


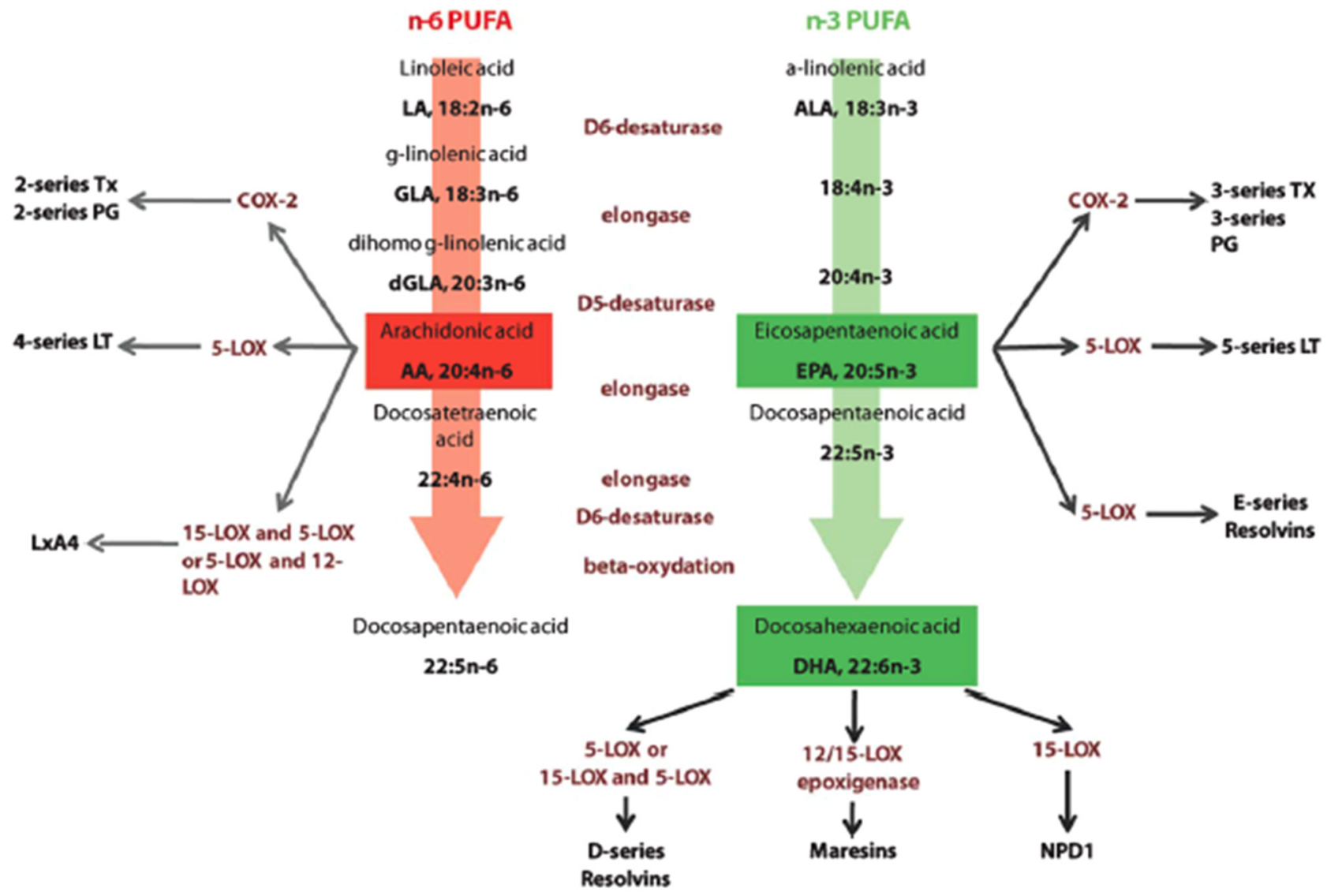

Fig. 1. Pathways in active eicosanoid metabolism from arachidonic acid, eicosapentaenoic acid and docosahexaenoic acid. $n-6$ and n-3 essential fatty acids precursors are linoleic acid (LA) and -linolenic acid (ALA). These precursors are metabolized into arachidonic acid (AA) and eicosapentaenoic (EPA) and docosahexaenoic acid (DHA) respectively. AA is metabolized into derivatives that belong to the eicosanoid family, series 2 and 4. EPA and DHA metabolic derivatives belong to the eicosanoid family, series 3 and 5, resolving family (series D and E) and neuroprotectins. Tx: thromboxane; PG: prostaglandines; COX-2: cycloxygenase 2; LT: leukotrienes; LOX: lipoxygenase; Lx: lipoxin; NPD1: neuroprotectin D1 (Laye, 2015).

and omega- 3 fatty acids catalyzed by the delta- 5 and delta- 6 desaturases, which suggests that individuals may require different amounts of dietary PUFAs or LC-PUFAs to achieve comparable biological effects. Furthermore, further studies addressing the biological effects of PUFAs and LCPUFAs should include genotyping for FADS1 and FADS2 polymorphisms.

\section{The opposing effects of omega- 6 and omega-3 fatty acids}

\subsection{Anti-inflammatory aspects: omega-3 fatty acids downregulate the expression of genes involved in inflammation and obesity}

Table 1 includes a summary of the opposing effects of omega- 6 and omega-3 fatty acids. Animal experiments and human studies have shown that EPA and DHA have the ability to upregulate and downregulate genes in various tissues including adipose tissue (Dahlman et al., 2005) and peripheral blood mononuclear cells (PBMCs) in humans (Crujeiras et al., 2008). Clinical studies indicate that inflammation is at the base of many diseases including cardiovascular disease, obesity, diabetes and even cancer. EPA and DHA have been shown to have beneficial effects in these conditions but the exact mechanisms by which EPA and DHA suppress inflammation are still under investigation. Previous studies have focused on the ability of EPA and DHA to suppress IL-1 $\beta$ and IL- 6 cytokines and to play an important role in the resolution of inflammation as well as through the production of resolvins E1 and E2, D1 and D2, and neuroprotectin D1 (Serhan et al., 2008)(Fig. 2). EPA and DHA activate peroxisome proliferator-activated receptor alpha $(\operatorname{PPAR} \alpha)$, which upregulates the expression of genes involved in lipid metabolism and downregulates the expression of genes involved in inflammation.

Recently, Bouwens et al. (Bouwens et al., 2009) studied the effects of the long-term intake of EPA and DHA on gene expression in Dutch elderly subjects participating in a doubleblind trial, by whole-genome transcriptomics analysis using PBMCs. The participants were randomly divided into three groups: group 1 received $1.8 \mathrm{~g} \mathrm{EPA}$ and $\mathrm{DHA} / \mathrm{d}$; group 2 received $0.4 \mathrm{~g}$ EPA and $\mathrm{DHA} / \mathrm{d}$ and group 3 received $4.0 \mathrm{~g}$ high-oleic acid sunflower oil (HOSF) for a period of 26 weeks. Blood samples were collected before and after the 26 weeks' intervention. Microarray analysis was performed on PBMC RNA from 23 subjects who received $1.8 \mathrm{~g}$ EPA and DHA/d and 

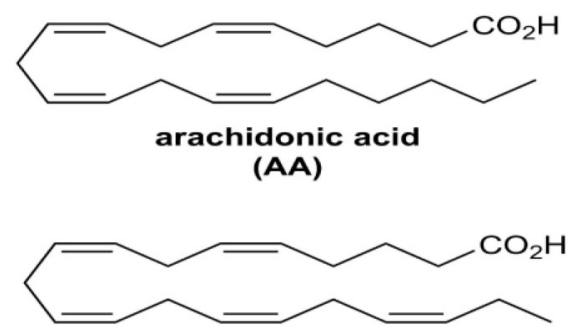

eicosapentaenoic acid

(EPA)
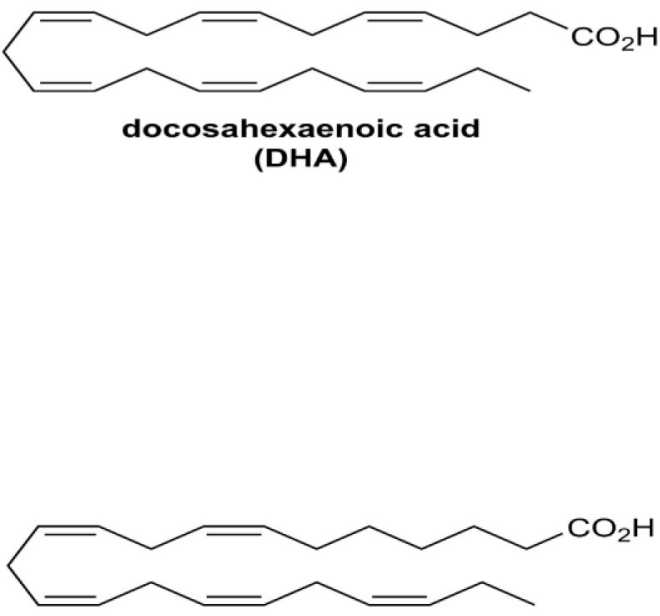

n-3 docosapentaenoic acid (n-3 DPA)
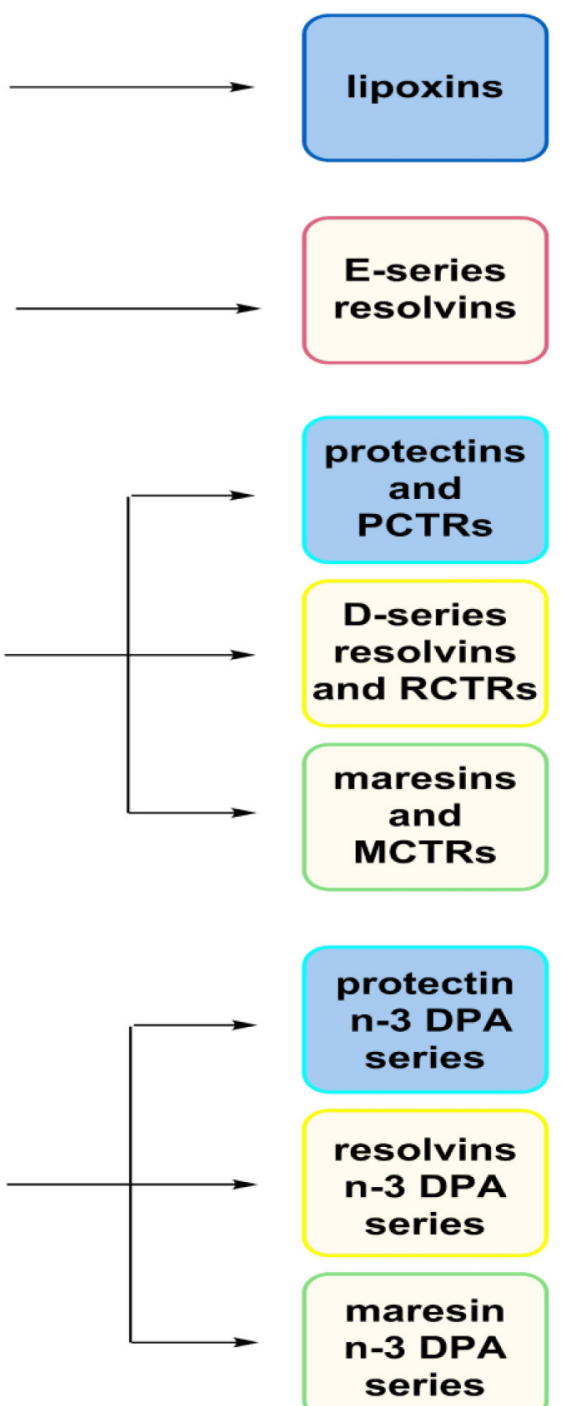

Fig. 2. The chemical structures of AA, EPA, DHA, and n-3 DPA and an outline of the individual families of SPMs biosynthesized from these PUFAs (Hansen et al., 2019).

25 subjects who received $4 \mathrm{~g}$ HOSF. Quantitative realtime polymerase chain reaction was performed on all 111 subjects. The high EPA and DHA supplementation of $1.8 \mathrm{~g} / \mathrm{d}$ changed the expression of 1040 genes, whereas HOSF changed the expression of 298 genes. Of these genes, 140 were overlapping between the groups, which resulted in 900 uniquely changed genes in the EPA and DHA group. Except for one gene, the direction of change of the overlapping genes was the same in the EPA and DHA and HOSF groups. The authors did a pathway analysis to determine the role of the genes that changed with EPA and DHA supplementation. GenMAPP analysis showed that supplementation with a high dose of EPA and DHA $1.8 \mathrm{~g} / \mathrm{d}$ for 26 weeks significantly decreased the expression of genes involved in inflammatory signaling pathways, such as eicosanoid synthesis, interleukin signaling, mitogen-activated protein kinase signaling, nuclear transcription factor and toll-like receptor, oxidative stress, cell adhesion, PPAR signaling, LXR/RXR (liver X receptor/ retinoid $X$ receptor), activation and hypoxia signaling in the cardiovascular system, interleukin receptors and several plaque stability-related metallopeptidases and adipogenesis.

In the HOSF group, which is high in oleic acid, there was also downregulation of genes involved in inflammation and cell adhesion. The low-dose $0.4 \mathrm{~g}$ of EPA and DHA also showed a downregulation of similar genes, but the effects were intermediate between the effect of the 1.8 high-dose EPA and DHA and the HOSF group. Unfortunately, the study did not include the omega- 6 fatty acid intake or the ratio of LA/ALA, AA/EPA or AA/EPA and DHA. In general, the addition of $1.8 \mathrm{~g}$ of EPA and DHA has decreased the omega-6/omega-3 ratio by $50 \%$ (Bouwens et al., 2009). The total amount of omega- 6 and omega- 3 of the background diet should be included in such studies to precisely determine the effect 1.8 EPA and DHA supplementation.

Kabir et al. (2007), in 2007, in 2007, in studying the effect of fish oil on adipose tissue, noted that $1.8 \mathrm{~g}$ of EPA and DHA decreased the total omega-6/omega-3 ratio in the plasma phospholipids from $12.9 \pm 1.1$ to $5.6 \pm 0.7$; total fat mass 
Table 1. Opposing effects of omega- 6 and omega- 3 fatty acids in obesity.

\begin{tabular}{|c|c|c|}
\hline & Omega-6 & Omega-3 \\
\hline Adipose cells (tissue) & $\uparrow$ & $\downarrow$ \\
\hline White adipose tissue & $\uparrow$ & $\downarrow$ \\
\hline Brown adipose tissue & $\downarrow$ & $\uparrow$ \\
\hline Inflammation & $\uparrow$ & $\downarrow$ \\
\hline Triglycerides & $\uparrow$ & $\downarrow$ \\
\hline Muscle glycogen synthesis & & $\uparrow$ \\
\hline $\begin{array}{l}\text { Endogenous antioxidants } \\
\text { (i.e. superoxide dismutase catalase), } \\
\text { glutathione peroxidase }\end{array}$ & $\downarrow$ & $\uparrow$ \\
\hline Oxidative stress & $\uparrow$ & $\downarrow$ \\
\hline \multicolumn{3}{|l|}{ Endocannabinoids } \\
\hline AEA & $\uparrow$ & $\downarrow$ \\
\hline 2-AG & $\uparrow$ & $\downarrow$ \\
\hline $\mathrm{CB} 1, \mathrm{CB} 2$ & $\uparrow$ & $\downarrow$ \\
\hline DHEA & & $\uparrow$ \\
\hline EPEA & & $\uparrow$ \\
\hline Protein synthesis & & $\uparrow$ \\
\hline Mitochondrial biogenesis & & $\uparrow$ \\
\hline$\beta$-oxidation & & $\uparrow$ \\
\hline AMPK & & $\uparrow$ \\
\hline Akt & & $\uparrow$ \\
\hline Telomeres & $\downarrow$ & $\uparrow$ \\
\hline NFk $\beta$ & $\uparrow$ & $\downarrow$ \\
\hline $\operatorname{PPAR} \alpha$ & $\downarrow$ & $\uparrow$ \\
\hline Leptin resistance & $\uparrow$ & $\downarrow$ \\
\hline Insulin resistance & $\uparrow$ & $\downarrow$ \\
\hline Adiponectin & & $\uparrow$ \\
\hline Uncoupling protein 1 gene expression & $\downarrow$ & $\uparrow$ \\
\hline Waist circumference & $\uparrow$ & $\downarrow$ \\
\hline Adipocyte size & $\uparrow$ & $\downarrow$ \\
\hline Appetite & $\uparrow$ & $\downarrow$ \\
\hline Food intake & $\uparrow$ & $\downarrow$ \\
\hline
\end{tabular}

$(P<0.019)$ and subcutaneous adipocyte diameter $(P$ $<0.0018$ ) were lower in the group receiving $1.8 \mathrm{~g}$ of EPA and DHA than in the placebo group. In addition, with EPA and DHA supplementation significant correlations were found between the adipocyte markers (adipocyte diameter and whole fat mass) and the main adipokines - plasma leptin and adiponectin - as well as plasma atherogenic factors (plasminogen activator inhibitor factor-1 (PAI-1), insulin and triacylglycerol). There was no correlation between adipocyte diameter and plasma tumor necrosis factor-alpha (TNF- $\alpha$ ) or plasma IL-6. As expected, adipocyte diameter and fat mass percentage were correlated with atherogenic (cysteine protease cathepsin S or CTSS) and inflammation-related genes (the chemoattractant gene plasminogen activator urokinase receptor, or PLAVR), the macrophage surface marker CD11b, and the macrophage phagocytic activity marker CD68. There was no change in weight but there was a significant loss in body fat mostly in the trunk and subcutaneous tissue, but not in the visceral tissue. After fish oil treatment, PAI-1 was lower whereas leptin, IL-6, TNF-a and serum amyloid A did not change significantly after 2 months with $1.8 \mathrm{~g}$ EPA and
DHA supplementation. The study of Kabir et al. (2007) points to the beneficial role of EPA and DHA to lower adiposity in humans. Another epidemiological study showed a correlation between adipocyte size and the omega- 6 and omega- 3 fatty acid content in subcutaneous abdominal adipose tissue in a group of overweight patients who had undergone abdominal surgery (Garaulet et al., 2006).

Micallef et al. (2009) studied the relationship between plasma omega-3 PUFA composition and weight status in 124 adults ( 21 healthy weight, 40 overweight and 63 obese). They found that higher omega-3 PUFA intake was associated with a healthier body mass index, waist circumference and hip circumference. Micallef et al. (2009) concluded that their findings suggest that omega-3 PUFAs may play a role in weight status and abdominal adiposity in humans. Couet et al. (1997) in 1997 showed that EPA and DHA supplementation reduced body fat mass and stimulated lipid oxidation in healthy adults. Others subsequently concluded that omega-3 fatty acid intake by itself or along with exercise increases weight loss (Mori et al., 1999; Hill et al., 2007). Caloric restriction is recommended for weight loss. Of interest is the fact that caloric restriction affects gene expression in a manner similar to EPA and DHA supplementation (Dahlman et al., 2005; Crujeiras et al., 2008). Crujeiras et al. (2008) used PBMCs to evaluate gene expression in Caucasian obese men on an eight-week low-calorie diet (LCD). All subjects lost at least $5 \%$ of body weight as a result of the hypocaloric diet. The microarray comparison between before and after the nutritional intervention resulted in 385 differentially expressed genes, with 158 genes overexpressed or upregulated and 227 genes downregulated after LCD. Genes encoding factors involved in nucleotide, DNA and chromatin metabolism as well as in cellular biosynthesis and regulation of metabolic processes, including protein and lipid metabolic pathways, were mostly upregulated $(P \leq 0.05)$ whereas those related to signal transduction cell communication, transport, immune response and carbohydrate metabolism were mostly downregulated. Of interest is the fact that IL-8, possibly a biomarker for fat mass, decreased after LCD and was associated with a higher fat mass decrease. A decrease in gene expression occurred in some specific oxidative stress and inflammation genes and related to body weight loss. Similar results have been previously reported in adipose tissue after a 28-day very LCD (Clement et al., 2004). It is possible that not only weight loss but also the negative energy balance could have influenced the regulation of genes involved in oxidative stress and inflammation. Caloric restriction by itself has been suggested to regulate adipose tissue gene expression independently of fat mass loss (Viguerie et al., 2005).

Many studies have shown that omega-3 fatty acids decrease adipose tissue development and lead to weight loss (Li et al., 2014; Du et al., 2015). A recent study based on the NIH Women's Health Initiative clearly showed the importance of the omega-6/omega-3 ratio in weight gain over a period of 10 years in healthy young women (Wang et al., 2016). High concentrations of omega- 6 in red blood cell membrane phospholipids were associated with increased risk in weight gain (Wang et al., 2016). Similarly, a high omega-6 to omega-3 ratio was associated with increased risk of weight gain, whereas a high concentration of omega- 3 fatty acids in red blood cell membrane phospholipids was associated with 
Table 2. Factors that affect outcomes in obesity and cardiovascular disease.

Lack to determine the composition of the background diet in terms of omega- 6 and omega- 3 fatty acids and inflammatory markers $i . e$. US, UK and Northern European countries have the highest amount of LA + AA in their diets, which competes with omega-3 PUFAs; they also have the lowest amount of vegetable and fruit intake, which are needed for optimal absorption of omega-3 PUFA from supplements

Background inflammation

Some studies are using fish and others omega-3 supplements; studies show that a continuous daily intake of omega-3 supplements leads to higher concentrations in the blood than eating fish two times/week

Variation in the dose of omega-3 fatty acids

Variation in the number of subjects

Variation in the severity of disease

Variation in the pharmacologic treatment

Genetic variants predisposing to cardiovascular disease

Dietary intake by means of questionnaires instead of actual measurements of omega-3 PUFAs in the red blood cell membrane

phospholipids or plasma is a major problem that leads to conflicting results

Length of intervention

Genetic variants in the metabolism of omega- 6 and omega-3 fatty acids

Low dose of EPA and DHA against a high intake of LA and AA of the background diet

decreased risk. This is a very important study because the investigators used red blood cell membrane phospholipids instead of dietary intake based on food frequency questionnaires that are not as accurate and lead to conflicting results in obesity studies in humans (Tab. 2). Dietary frequency questionnaires suffer from two very important deficiencies in carrying out studies on the relationship of essential fatty acids (omega-6 and omega-3). One is the well-known inaccuracy based on the memory of what people ate, and the other is the variation in the endogenous production of omega- 6 and omega- 3 fatty acids. What is actually being circulated in the blood and in red blood cell membrane phospholipids consists of dietary intake and the endogenous production of omega- 6 and omega- 3 fatty acids. These two factors account for the discrepancy in epidemiological, observational, and clinical intervention studies along with other factors, which must be taken into consideration while carrying out clinical intervention studies in obesity (Tab. 2).

\section{Endocannabinoids and obesity}

The brain is enriched in AA and DHA. Both are essential for optimal brain development and function. Increased dietary intake of DHA and EPA has shown beneficial effects on learning and memory, synaptic plasticity, neurogenesis and neuroinflammatory processes. AA, EPA and DHA are precursors to many bioactive lipid mediators, including endocannabinoids (Dyall and Michael-Titus, 2008).

The endocannabinoid system is made up of the cannabinoid receptors (CB1 and $\mathrm{CB} 2$ receptors), endocannabinoids and the enzymes required for endocannabinoid synthesis and degradation (De Petrocellis and Di Marzo, 2009). Two families of endocannabinoids have been identified, 2-acylglycerols and ethanolamides. The most abundant and the best-characterized endocannabinoids in the brain are the 2-acylglycerol, 2-arachidonoylglycerol (2-AG) and the ethanolamide, N-arachidonoylethanolamine (AEA, anandamide), which are both derived from AA (Katona and Freund, 2012).
The omega-3 fatty acids produce endocannabinoids as follows, alpha-linolenoylethanolamide (ALEA) is produced from ALA and has been identified in human plasma, where levels were shown to be responsive to dietary ALA supplementation (Jones et al., 2014). But the best-characterized endocannabinoids are produced from EPA and DHA, with 2-acylglycerols, 2-docosahexaenoylglycerol (2-DHG) and 2eicosapentaenoylglycerol (EPG), and the ethanolamides, Ndocosahexaenoylethanolamine (DHEA) and N-eicosapentaenoylethanolamine (EPEA). Chronic DHA and EPA supplementation reduces 2-AG and AEA (derived from AA) levels across a range of tissues including the brain, with reciprocal increases in levels of DHEA and 2-DHG, and 2-EPG (Watanabe et al., 2003; Artmann et al., 2008; Matias et al., 2008; Batetta et al., 2009; Wood et al., 2010). These alterations suggest competition for shared biosynthetic pathways as DHA and EPA displace AA from membrane phospholipids.

AEA and 2-AG function at the guanine-nucleotide-binding protein (G protein)-coupled receptor (GPCR) cannabinoid receptors, CB1 and CB2 (Di Marzo et al., 2015). The CB1 receptor is widely expressed in the brain, where it is highly expressed in the cortex, hippocampus, cerebellum and basal ganglia. CB2 receptors were initially identified in cells in the immune system (Patel et al., 2010), but are also found in glia cells and subsets of neurons. AEA and 2-AG bind to CB1 and CB2 leading to activation of pathways to initiate food intake in the limbic system, hypothalamus and hindbrain. AEA is a ligand for $\mathrm{CB} 1$, with a reduced affinity for $\mathrm{CB} 2$, whereas $2-\mathrm{AG}$ binds to both receptors.

Omega-3 fatty acid derived N-acylethanolamines (NAEs) from DHA, DHEA and EPEA derived from EPA are known for their anti-inflammatory effects and their opposing effects of the AEA and 2-AG in various tissues and brain. EPA and DHA modulate endocannabinoid synthesis due to their ability to displace AA from membrane phospholipids, which leads to greater production of EPEA and DHEA. While they do not affect appetite, they have anti-inflammatory properties. DHA counteracts the conversion of AA to AEA and stops the 
transfer of AA to the sn-1 position of phospholipids, from which AA can be converted to AEA. Supplementation studies in both humans and animals have found that EPA and DHA decrease 2-AG (Batetta et al., 2009; Banni et al., 2011) and AEA levels in obese subjects with a reduction in the plasma omega-6/omega-3 ratio and a decrease in CB2 mRNA expression leading to decreased receptor stimulation. Furthermore, animal and human studies have also found that EPA and DHA supplementation lowers brain 2-AG levels (Di Marzo et al., 2010), body mass index (Thorsdottir et al., 2007) and prevents the development of obesity and further weight gain in mouse models (Rossmeisl et al., 2012). The decrease in obesity may be due to increased b-oxidation (Frøyland et al., 1997) a reduction in AEA and 2-AG production, decreasing cannabinoid receptor stimulation and therefore decrease appetite and food intake. Other possibilities for the weightloss could be the EPA and DHA increasing body insulin sensitivity by inhibiting LPS induced phosphorylation, NF-KB dysregulation and increasing Akt phosphorylation, and GLU-4 transporter translocation via GPR120 dependent pathway (Oh et al., 2010).

The concentrations of endocannabinoids are regulated by: - dietary intake of omega-6 and omega-3 fatty acids;

- by the activity of biosynthetic and catabolic enzymes involved in the endocannabinoid pathway, which is an important player in the regulation of appetite and metabolism (Banni and Di Marzo, 2010).

The endocannabinoid system is involved in regulation of energy balance and sustained hyperactivity of the endocannabinoid system contributes to obesity (Banni and Di Marzo, 2010). Increasing the precursor pool of AA causes excessive endocannabinoid signaling leading to weight gain and a metabolic profile associated with obesity. Endocannabinoids activate endogenous cannabinoid $\mathrm{CB} 1$ and $\mathrm{CB} 2$ receptors in the brain, liver, adipose tissue, and the gastrointestinal tract. Activation of $\mathrm{CB} 1$ receptors in the hypothalamus leads to increased appetite and food intake. In mouse experiments, endocannabinoids selectively enhance sweet taste, which in the current highly palatable food supply stimulate food intake (Yoshida et al., 2010). The endocannabinoid system functions in concert with other systems regulating food intake and energy balance, and is regulated by leptin, insulin, ghrelin, cholecystokinin, and other signals. Targeting the endocannabinoid system has been a strategy for weight loss. Randomized controlled clinical trials in overweight or obese humans showed that $\mathrm{CB} 1$ receptor antagonists such as rimonabant led to significant weight loss after one year of treatment (Van Gaal et al., 2008). However, the drug was withdrawn from the market due to severe side effects that led to increased risk of anxiety, depression, and suicide.

Alvheim et al. (2014) carried out an experiment in mice at six weeks of age, in which increasing the linoleic acid in the diet led to increases in AA in red blood cell membrane phospholipids, elevated 2-AG and AEA in liver, elevated plasma-leptin and resulted in larger adipocytes and more macrophage infiltration in adipose tissue. It was also noted that a higher linoleic acid increased feed efficacy and caused greater weight gain than isocaloric diets containing less LA. Increasing the dietary LA from 1 to $8 \%$ of energy increased liver endocannabinoid levels, which increased the risk of developing obesity, even in a low-fat diet. Mice chronically deficient in omega-3 PUFA have significantly lower concentrations of DHA in brain phospholipids, and higher 2-AG (derived from AA) compared to mice with sufficient omega-3 PUFA in their diet. Furthermore, omega-3 PUFA supplementation of mice with $10 \%$ weight DHA-rich fish oil for 4 weeks led to higher brain DHA levels compared to mice on a low omega-3 PUFA diet, and led to a significant decrease in brain 2-AG and brain AA. This nutritional approach with dietary omega-3 PUFA, reversed the dysregulation of the cannabinoid system, improved insulin sensitivity and decreased central body fat.

A diet high in the omega-6/omega-3 ratio causes an increase in the endocannabinoid signaling and related mediators, which lead to an increased inflammatory state, disturbed energy homeostasis, and mood. In animal experiments a high omega- 6 fatty acid intake leads to decreased insulin sensitivity in muscle and promotes fat accumulation in adipose tissue. Nutritional approaches with dietary omega-3 fatty acids reverse the dysregulation of this system, improve insulin sensitivity and control body fat.

\section{Genetics}

\subsection{The fat mass and obesity-associated gene}

Genome-wide association studies (GWAS) have identified more than 90 loci that contain genetic variants associated with obesity. Many of these variants are in intronic regions. The strongest genetic association with risk to polygenic obesity are single-nucleotide variants (SNV) in intron 1 and 2 of the FTO (fat mass and obesity associated) gene. There are 89 SNVs in FTO intron 1 and 2. Deciphering how these variants regulate gene expression has been difficult. Recently, Claussnitzer et al. (2015) reported a strategy and defined the causal SNV and the mechanisms of function in preadipocytes. The authors provide evidence for the rs $1421085 \mathrm{~T}$ to $\mathrm{C} \mathrm{SNV}$ to result in a cellular phenotype consistent with obesity in primary human adipocytes, including decreased mitochondrial energy generation and increased triglyceride accumulation.

Their study provided evidence that the risk allele rs 1411085 T to C SNV resulted in increased expression of IRX3 and IRX5 genes in pre-adipocytes, which shifted the development of these cells toward the "white program" and increased lipid storage, whereas knockdown of IRX3 and IRX5 genes restored thermogenesis in adipocytes from persons at high risk for obesity. Thus, the risk allele functioned similarly to AA metabolites, PGE2 and PGF2a, increasing proliferation of white adipose tissue and decreasing its browning respectively, whereas the knockdown of IRX3 and IRX5 genes functioned similarly to omega-3 fatty acid metabolites increasing the browning of the adipose tissue, mitochondrial biogenesis and thermogenesis. Human studies have shown a direct relationship between plasma arachidonic acid levels and infant body weight, as well as between AA levels in adipose tissue lipids and BMI in children in Cyprus and Crete (Jensen et al., 1997; Savva et al., 2004). AA directly inhibits UCPI gene expression. Considering the high omega-6/ omega-3 fatty acid ratio of Western diets and the role of AA in adipose cell differentiation, proliferation, and decreasing browning of white adipose tissue, further research should 
include studies on the effects of omega-3 fatty acids in blocking the effects of the risk allele (rs 1421085), which appears to be responsible for the association between the first intron of FTO gene and obesity in humans.

\subsection{Omega-3 fatty acids and GPR120}

GPR120 is a lipid-sensing receptor highly expressed in proinflammatory macrophages, and omega-3 fatty acids exert their anti-inflammatory, insulin-sensitizing effects through this receptor. This same system functions in the hypothalamus. Cintra et al. (2012) have shown that i.c.v. administration of omega-3 fatty acids into obese rats exerts local antiinflammatory effects, through the hypothalamic GPR120 receptor, which leads to lower food intake, weight loss, and improved insulin-sensitivity.

GPR120 is an omega-3 fatty acid receptor/sensor, and loss of function leads to obesity and insulin resistance in humans. A small fraction about $3 \%$ of obese carry a loss- of-function, nonsynonymous GPR120 variant $(\mathrm{R} 270 \mathrm{H})$ that exhibits impaired intrinsic signaling properties and inhibits omega-3 fatty acids stimulation of weight GPR120. In European populations, this variant is associated with increased risk for obesity and insulin resistance, and high-fat-fed GPR120 KO mice also develop obesity and insulin resistance (Ichimura et al., 2012). Thus, diminished activation of GPR 120 can be an important contributor to obesity, insulin resistance, and tissue inflammation in both mice and men. The human studies were conducted by Ichimura primarily in a European population (Ichimura et al., 2012). It will be therefore important to confirm these findings to other ethnic groups. The frequency of the mutant receptors in the population would account for the different results obtained with omega- 3 fatty acids, relative to food intake, weight loss, insulin resistance and antiinflammatory effects. Since the R270H variant behaves as a dominant negative with respect to GPR120 function, metabolic differences would be expected in the $\mathrm{R} 270 \mathrm{H}$ patients.

\section{Polygenic score revealing susceptibility to obesity}

Twin studies have shown that overweight and obesity are highly heritable. However, genetic studies so far have failed to identify genetic variants with high frequency. In fact, single genetic variants such as the melanocortin 4 receptor (MC4R) gene which have a large effect are very rare in the population. For most people with severe obesity, there is no single genetic cause. In such cases, genetic susceptibility may result from cumulative effects of many variants with individual modest effects, a polygenic model, in which each variant has a small effect, but taken together, indicate a persons' overall risk.

Polygenic scores based on Genome-wide association studies (GWAS) have been used in other chronic diseases such as cardiovascular disease (CVD) and cancer. Earlier studies using genome-wide polygenic score (GPS) (Locke et al., 2015) to predict susceptibility to obesity showed the strongest association to a common variant of the FTO locus. The risk allele was associated with a statistically significant, but clinically modest increase in weight of about $1 \mathrm{~kg}$ per inherited risk allele. Previous efforts to create an effective polygenic score for obesity had a modest success (Loos and Janssens, 2017). Recently, Khera et al. (2019) developed computational algorithms and large data sets to derive, validate, and test a robust polygenic predictor of BMI and obesity. This genome-wide GPS integrates all available common variants into a single quantitative measure of inherited susceptibility to obesity. The GPS identifies a subset of the adult population that is at substantial risk of severe obesity, while others are considerably protected. It is associated with very small differences in birthweight, but it predicts clear differences in weight during early childhood and major differences in weight trajectory and risk of developing severe obesity in subsequent years.

The identification of genetic predisposition to obesity that quantifies inherited susceptibility to obesity provides new opportunities for its prevention. Diet and exercise have been considered in the prevention and management of obesity with promising results. Our genes were programmed to respond to a diet that was consistent with the evolutionary aspects of diet, which in terms of fatty acids was characterized by a balanced omega-6/omega-3 fatty acid ratio. With the current emphasis on plant-based diets, high in vegetable oils rich in omega-6 fatty acids, particular attention must be paid to decreasing the omega- 6 rich oils and increase the intake of omega- 3 rich oils and monounsaturates, leading to a balanced omega-6/omega-3 ratio. Obesity is characterized by a chronic inflammatory state and by an overactive endocannabinoid system with high levels of AEA and 2-AG derived from AA through a high linoleic acid intake and endogenous metabolism. Endocannabinoids are made from fats. Dietary fats are the only source of fat required for the synthesis of endocannabinoids from AA, unless there is increased endogenous production of AA from genetic variants in the FADS1 and FADS2. A high production of AEA and 2-AG from AA influence GPCR signaling with subsequent increase in appetite and food intake, leading to obesity.

\section{Conclusions and recommendations}

It is evident that a balanced omega-6/omega- 3 ratio is important to health. A high omega- 6 fatty acid intake such as LA leads to a prothrombotic and proinflammatory state as a result of the increased production of proinflammatory leukotrienes, which further lead to increased production of cytokines. LA metabolizes to AA, which produces AEA and 2AG that lead to hyperactivity of the endocannabinoid system increasing appetite and food intake. The current food supply is very high in LA. Individuals that carry genetic variants in FADS1 and FADS2, which increase the production of AA from LA are particularly vulnerable to obesity, due to higher levels of AA and increased production of AEA and 2-AG, increasing appetite, affecting energy intake and body weight. Obese individuals have higher amounts of AEA and 2-AG and an overactive endocannabinoid system. Obesity levels are escalating, and there is a deficiency of both EPA and DHA and an excessive LA, and AA intake worldwide. Because dietary guidelines emphasize plant-based fats high in omega- 6 fatty acids, it is essential that every effort be made to return the omega3 fatty acids into the food supply and balance the omega-6/ omega-3 ratio (Simopoulos, 1998). Public health messages must 
be directed towards prevention of overweight and obesity. Lowering LA and increasing EPA and DHA is essential for the management of obesity. In the future, data from GPS will identify persons at risk for genetic susceptibility to obesity, who will need to modify dietary fat intake in order to attain a balanced omega-6/ omega-3 fatty acid ratio for health.

Future studies will continue to provide data on mechanisms of nutrients and gene interactions in both health and disease. It is necessary to bridge successfully the rapidly widening gap between gene nutrient disease association research, and the critical investigations needed to be carried out to improve clinical management and public health. A process needs to be established to define when genomic discoveries such as genenutrient-disease associations are 'ready' to be evaluated as potential tools for personalized nutrition to improve public health.

\section{References}

Alvheim AR, Torstensen BE, Lin YH, et al. 2014. Dietary linoleic acid elevates the endocannabinoids 2-AG and anandamide and promotes weight gain in mice fed a low-fat diet. Lipids 49: 59-69.

Artmann A, Petersen G, Hellgren LI, et al. 2008. Influence of dietary fatty acids on endocannabinoid and $\mathrm{N}$-acylethanolamine levels in rat brain, liver and small intestine. Biochim Biophys Acta 1781: 200-212.

Banni S, Di Marzo V. 2010. Effect of dietary fat on endocannabinoids and related mediators: consequences on energy homeostasis, inflammation and mood. Mol Nutr Food Res 54: 82-92.

Banni S, Carta G, Murru E, et al. 2011. Krill oil significantly decreases 2-arachidonoylglycerol plasma levels in obese subjects. Nutr Metabol 8.

Batetta B, Griinari M, Carta G, et al. 2009. Endocannabinoids may mediate the ability of (n-3) fatty acids to reduce ectopic fat and inflammatory mediators in obese Zucker rats. J Nutr 139(8): 1495-1501.

Bouwens M, van de Rest O, Dellschaft N, et al. 2009. Fish oil supplementation induces anti-inflammatory gene expression profiles in human blood mononuclear cells. Am J Clin Nutr 90: 415-424.

Burdge G. 2004. Alpha-linolenic acid metabolism in men and women: nutritional and biological implications. Curr Opin Clin Nutri Metab Care 7: 137-144.

Cho HP, Nakamura MT, Clarke SD. 1999. Cloning, expression, and nutritional regulation of the mammalian delta- 6 desaturase. $J$ Biol Chem 274: 471-477.

Cho HP, Nakamura M, Clarke SD. 1999. Cloning, expression, and fatty acid regulation of the human delta-5 desaturase. $J$ Biol Chem 274: 37335-37339.

Cintra DE, Ropelle ER, Moraes JC, et al. 2012. Plos One 7: e30571.

Claussnitzer M, Dankel SN, Kim KH, et al. 2015. FTO obesity variant circuitry and adipocyte browning in humans. $N$ Engl $J$ Med 373: 895-907.

Clement K, Viguerie N, Poitou C, et al. 2004. Weight loss regulates inflammation-related genes in white adipose tissue of obese subjects. FASEB J 18: 1657-1669.

Couet C, Delarue J, Ritz P, Antoine JM, Lamisse F. 1997. Effect of dietary fish oil on body fat mass and basal fat oxidation in healthy adults. Int J Obes Relat Metab Disord 21: 637-643.

Crujeiras AB, Parra D, Milagro FI, et al. 2008. Differential expression of oxidative stress and inflammation related genes in peripheral blood mononuclear cells in response to a low-calorie diet: a nutrigenomics study. OMICS 12: 251-261.

Dahlman I, Linder K, Arvidsson Nordström E, et al. 2005. Changes in adipose tissue gene expression with energy-restricted diets in obese women. Am J Clin Nutr 81: 1275-1285.

De Petrocellis L, Di Marzo V. 2009. An introduction to the endocannabinoid system: from the early to the latest concepts. Best Pract Res Clin Endocrinol Metab 23: 1-15.

Di Marzo V, Griinari M, Carta G, et al. 2010. Dietary krill oil increases docosahexaenoic acid and reduces 2-arachidonoylglycerol but not $\mathrm{N}$-acylethanolamine levels in the brain of obese Zucker rats. Int Dairy J 20(4): 231-235.

Di Marzo V, Stella N, Zimmer A. 2015. Endocannabinoid signalling and the deteriorating brain. Nat Rev Neurosci 16: 30-42.

Du S, Jin J, Fang W, Su Q. 2015. Does fish oil have an anti-obesity effect in overweight/obese adults? A meta-analysis of randomized controlled trials. Plos One 10(11): e0142652.

Dyall SC, Michael-Titus AT. 2008. Neurological benefits of omega-3 fatty acids. Neuromol Med 10: 219-235.

Frøyland L, Madsen L, Vaagenes H, et al. 1997. Mitochondrion is the principal target for nutritional and pharmacological control of triglyceride metabolism. J Lipid Res 38(9): 1851-1858.

Garaulet M, Hernandez-Morante JJ, Lujan J, Tebar FJ, Zamora S. 2006. Relationship between fat cell size and number and fatty acid composition in adipose tissue from different fat depots in overweight/obese humans. Int J Obes (Lond) 30: 899-905.

Hansen TV, Vik A, Serhan CN. 2019. The protectin family of specialized pro-resolving mediators: potent immunoresolvents enabling innovative approaches to target obesity and diabetes. Front Pharmacol 9: 1582.

Hill AM, Buckley JD, Murphy KJ, Howe PR. 2007. Combining fishoil supplements with regular aerobic exercise improves body composition and cardiovascular disease risk factors. Am J Clin Nutr 85: 1267-1274.

Ichimura A, Hirasawa A, PoulainGodefroy O, et al. 2012. Dysfunction of lipid sensor GPR120 leads to obesity in both mouse and human. Nature 483: 350-354.

Jensen CL, Prager TC, Fraley JK, Chen H, Anderson RE, Heird WC. 1997. Effect of dietary linoleic/alpha-linolenic acid ratio on growth and visual function of term infants. J Pediatr 131: 200-209.

Jones PJ, Lin L, Gillingham LG, Yang H, Omar JM. 2014. Modulation of plasma N-acylethanolamine levels and physiological parameters by dietary fatty acid composition in humans. $J$ Lipid Res 55: 2655-2664.

Kabir M, Skurnik G, Naour N, et al. 2007. Treatment for 2 mo with n3 polyunsaturated fatty acids reduces adiposity and some atherogenic factors but does not improve insulin sensitivity in women with type 2 diabetes: a randomized controlled study. Am J Clin Nutr 86: 1670-1679.

Katona I, Freund TF. 2012. Multiple functions of endocannabinoid signaling in the brain. Annu Rev Neurosci 35: 529-558.

Khera AV, Chaffin M, Wade KH, et al. 2019. polygenic prediction of weight and obesity trajectories from birth to adulthood. Cell 177 (3): 587-596.e9.

Laye S., et al. 2015. N-3 polyunsaturated fatty acid and neuroinflammation in aging and Alzheimer's disease. Nutr Aging 3: $33-47$.

Li J, Li FR, Wei D, et al. 2014. Endogenous-3 polyunsaturated fatty acid production confers resistance to obesity, dyslipidemia, and diabetes in mice. Mol Endocrinol 28(8): 1316-1328.

Locke AE, et al. 2015. Genetic studies of body mass index yield new insights for obesity biology. Nature 518(7538): 197-206. 
Loos RJF, Janssens ACJW. 2017. Predicting polygenic obesity using genetic information. Cell Metab 25(3): 535-543.

Marquardt A, Stohr H, White K, Weber BH. 2000. Cdna cloning, genomic structure, and chromosomal localization of three, members of the human fatty acid desaturase family. Genomics 66: $175-183$.

Matias I, Carta G, Murru E, Petrosino S, Banni S, Di Marzo V. 2008. Effect of polyunsaturated fatty acids on endocannabinoid and Nacyl-ethanolamine levels in mouse adipocytes. Biochim Biophys Acta 1781: 52-60.

Micallef M, Munro I, Phang M, Garg M. 2009. Plasma n-3 polyunsaturated fatty acids are negatively associated with obesity. Br J Nutr 1-5.

Mori TA, Bao DQ, Burke V, Puddey IB, Watts GF, Beilin LJ. 1999. Dietary fish as a major component of a weight-loss diet: effect on serum lipids, glucose, and insulin metabolism in overweight hypertensive subjects. Am J Clin Nutr 70: 817-825.

Naughton SS, Mathai ML, Hryciw DH, McAinch AJ. 2013. Fatty acid modulation of the endocannabinoid system and the effect on food intake and metabolism. Int J Endocrinol 2013: 361895.

Oh DY, Talukdar S, Bae EJ, et al. 2010. GPR120 is an omega-3 fatty acid receptor mediating potent anti-inflammatory and insulinsensitizing effects. Cell 142(5): 687-698.

Patel KD, Davison JS, Pittman QJ, Sharkey KA. 2010. Cannabinoid $\mathrm{CB}(2)$ receptors in health and disease. Curr Med Chem 17: 1393-1410.

Rossmeisl M, Jilkova ZM, Kuda O, et al. 2012. Metabolic effects of N-3 PUFA as phospholipids are superior to triglycerides in mice fed a high-fat diet: possible role of endocannabinoids. Plos One 7 (6, article e38834).

Savva SC, Chadjigeorgiou C, Hatzis C, et al. 2004. Association of adipose tissue arachidonic acid content with BMI and overweight status in children from Cyprus and Crete. $\mathrm{Br} J$ Nutr 91: 643-649.

Schaeffer L, Gohlke H, Muller M, et al. 2006. Common genetic variants of the FADS1 FADS2 gene cluster and their reconstructed haplotypes are associated with the fatty acid composition in phospholipids. Hum Mol Genet 15: 1745-1756.

Serhan CN, Chiang N, Van Dyke TE. 2008. Resolving inflammation: dual anti-inflammatory and pro-resolution lipid mediators. Nat Rev Immunol 8: 349-361.

Simopoulos AP. 1991. Omega-3 fatty acids in health and disease and in growth and development. Am J Clin Nutr 54: 438-463.

Simopoulos AP, ed. The return of w3 fatty acids into the food supply. I. Land-based animal food products and their health effects, World Review of Nutrition and Dietetics 83 Karger Basel 1998.
Simopoulos AP. 2008. The importance of the omega-6/omega-3 fatty acid ratio in cardiovascular disease and other chronic diseases. Exp Biol Med (Maywood) 233:674-688.

Simopoulos AP. Omega-6/omega-3 essential fatty acids: biological effects. In Simopoulos AP, Bazan NG, eds. Omega-3 fatty acids, the brain and retina. World Review of Nutrition and Dietetics vol. 99. Basel: Karger, 2009, pp. 1-16.

Simopoulos AP. 2010. Genetic variants in the metabolism of omega-6 and omega-3 fatty acids: their role in the determination of nutritional requirements and chronic disease risk. Exp Biol Med (Maywood) 235(7): 785-795.

Simopoulos AP, Robinson J. 1999. The omega diet. The lifesaving nutritional program based on the diet of the Island of Crete. New York: HarperCollins.

Simopoulos AP, Norman HA, Gillaspy JE, Duke JA. 1992. Common purslane: a source of omega-3 fatty acids and antioxidants. $\mathrm{J} \mathrm{Am}$ Coll Nutr 11:374-382.

Stark KD, Van Elswyk ME, Higgins MR, Weatherford CA, Salem N Jr. 2016. Global survey of the omega-3 fatty acids, docosahexaenoic acid and eicosapentaenoic acid in the blood stream of healthy adults. Prog Lipid Res 63: 132-152.

Thorsdottir I, Tomasson H, Gunnarsdottir I, et al. 2007. Randomized trial of weight-loss-diets for young adults varying in fish and fish oil content. Int J Obes 31(10): 1560-1566.

Van Gaal L, Pi-Sunyer X, Despres JP, McCarthy C, Scheen A. 2008. Efficacy and safety of rimonabant for improvement of multiple cardiometabolic risk factors in overweight/obese patients: pooled 1-year data from the Rimonabant in obesity (RIO) program. Diabetes Care 31: S229-S240.

Viguerie N, Poitou C, Cancello R, Stich V, Clement K, Langin D. 2005. Transcriptomics applied to obesity and caloric restriction. Biochimie 87: 117-123.

Wang L, Manson JE, Rautiainen S, et al. 2016. A prospective study of erythrocyte polyunsaturated fatty acid, weight gain, and risk of becoming overweight or obese in middle-aged and older women. Eur J Nutr 55(2): 687-697.

Watanabe S, Doshi M, Hamazaki T. 2003. n-3 polyunsaturated fatty acid (PUFA) deficiency elevates and n-3 PUFA enrichment reduces brain 2-arachidonoylglycerol level in mice. Prostaglandins Leukot Essent Fatty Acids 69: 51-59.

Wood JT, Williams JS, Pandarinathan L, Janero DR, Lammi-Keefe CJ, Makriyannis A. 2010. Dietary docosahexaenoic acid supplementation alters select physiological endocannabinoid-system metabolites in brain and plasma. J Lipid Res 51: 1416-1423.

Yoshida R, Ohkuri T, Jyotaki M, et al. 2010. Endocannabinoids selectively enhance sweet taste. Proc Natl Acad Sci USA 107: 935-939.

Cite this article as: Simopoulos AP. 2020. Omega-6 and omega-3 fatty acids: Endocannabinoids, genetics and obesity. OCL 27 : 7. 